\title{
PRIVACY CRISIS IN CONTEMPORARY ARCHITECTURE WITH CONCENTRATION ON CONTEMPORARY ARCHITECTURE IN JEDDEH CITY AS A MODEL
}

\section{Ahmed Helal Mohammed}

Professor of Architectural designs, King Abdeh Aziz University, Jeddeh, POB 8020 Jeddeh 21589,Email:dra_helal@yahoo.com.

\section{Amar sadeq Dahlan}

Head of the Architecture department, Faculty of Environmental Designs, Jeddeh,POB 8020 Jeddeh 21589

\section{(Received August 14, 2008 Accepted August 27, 2008)}

After checking the architecture of the city, it is noted that the structure of the city does not suit the traditions and values of our society and religion. The structure is disconnected and characterized by its separation and the design is based on outside shape which gives an impression of separation and isolation. For architectural aspects, such as the privacy which is considered one of the most important characters of architectural aspects, the designer neglected this value because he is imitating and transferring the models of western architecture, and those models lacked any regulations for holes and frames places that are required to achieve privacy, thus the inhabitants obliged to use various methods to achieve privacy for their houses The buildings multiuse and as it closed to each other lead to the lack of audio privacy. The researcher concluded that the contemporary architecture lacked privacy as a result of many factors. The researcher also concluded that the preview of contemporary architecture in Jeddeh city reflects the lacking of privacy, thus contemporary architecture lacked audio or visual privacy.

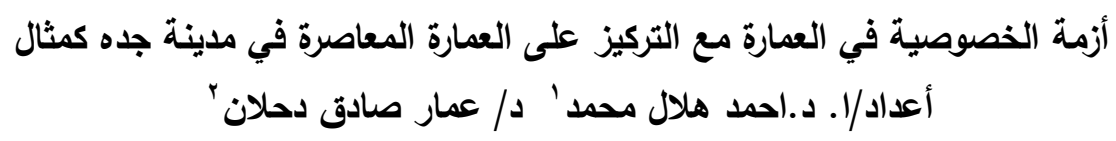

الملخص

المتأمل لعمارة المدينة المعاصرة يلاحظ أن النسيج العمراني يأخذ طابعا لا يناسب تقاليد

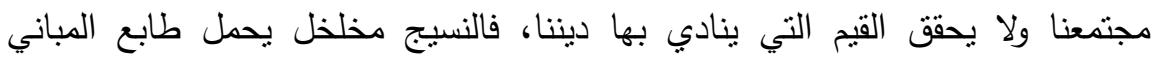

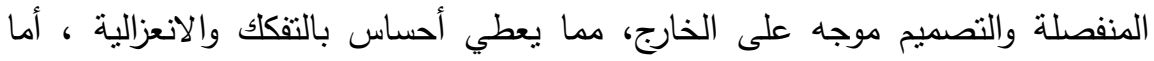

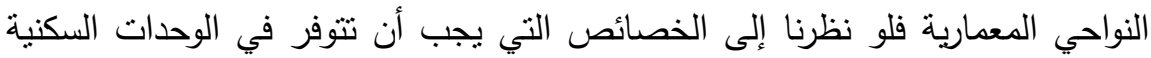

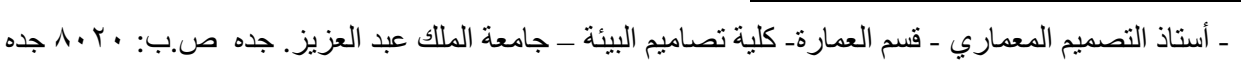

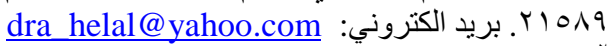

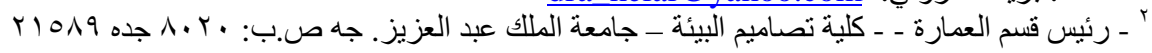


وأهمهما الخصوصية نجد أن هذه القيمة غابت عن المصمم بسبب نقل وتقليد العمارة

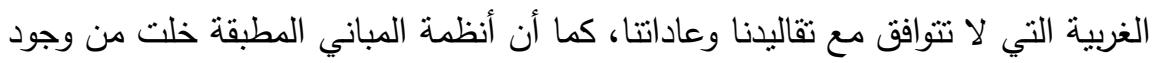
أي اشتراطات منظمة لاماكن الفتحات أو البروزات لتحقيق الخصوصية لهذا يلجا السكان النيان

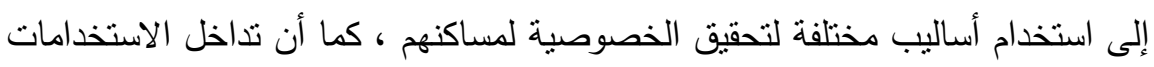

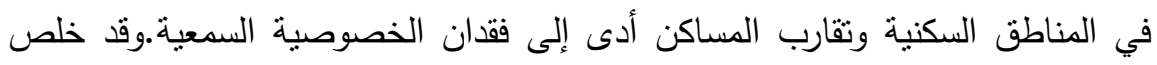

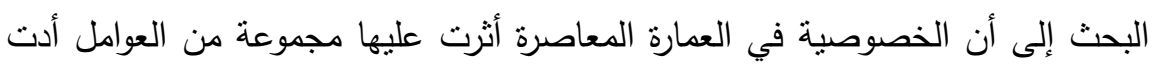

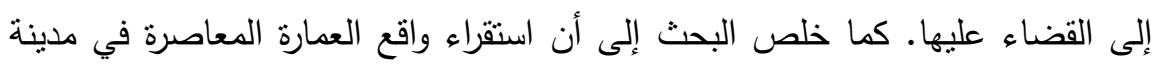

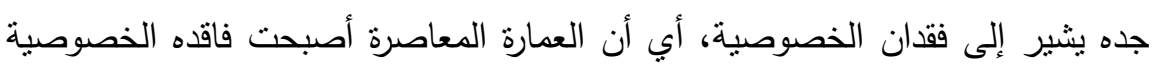
سواء كانت بصرية أو سمعية.

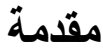

يحتاج الأفراد والجماعات إلى الخصوصية كمطلب من منطلبات حياتهم اليومية، ويختلف هذا الاحتباج باختلاف الوسط الذي يعيشون فيه ، كما تختلف درجات الخصوصية في المجتمع الواحد لعوامل كثيرة ،

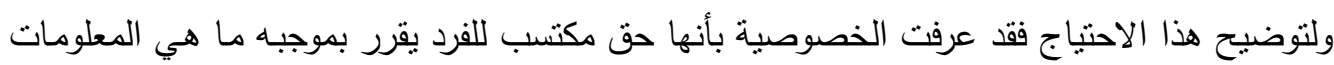

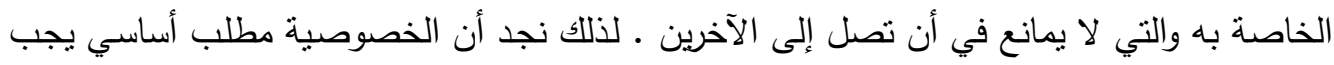
أن يراعى عند تصميم أب فراغ يستخدمه الناس ، وتعتبر الخصوصية من أهم العوامل التي تؤثر على لأنى

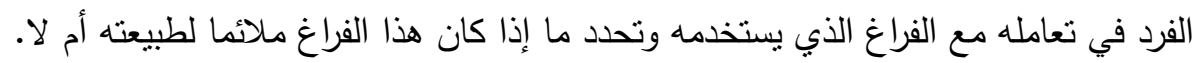

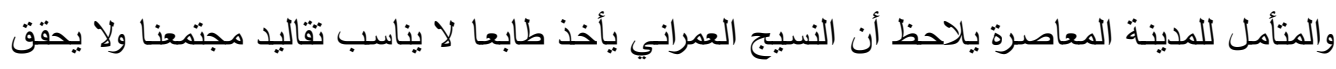

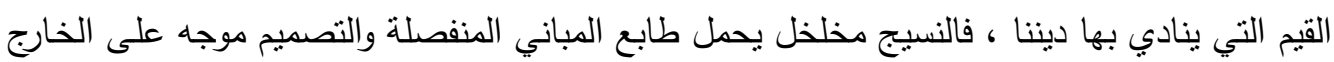

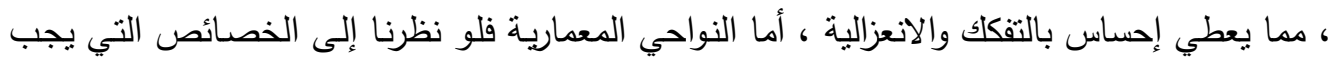

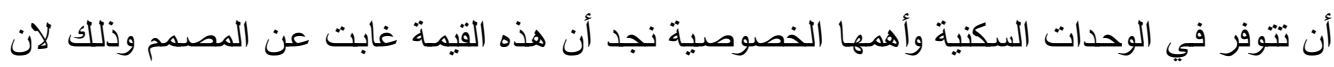
السبب الرئيسي هو نقل وتقليد للعمارة الغربية التي لا تتوافق مع تقاليدنا وعادتتا ـ كما أن أنظمة المباني

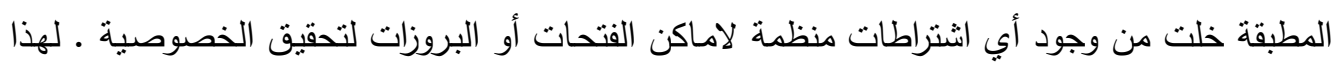

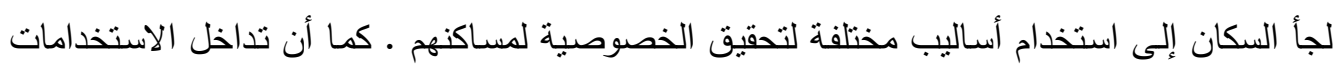
في المناطق السكنية أدى إلى فقدان الخصوصية السمعية. من هنا كانت هذه الورقة البحثنة لدراسة الخصوصية في العمارة المعاصرة ، ودراسة العوامل التي أثرت

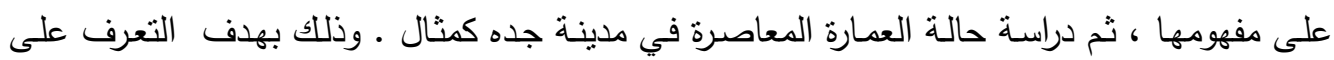

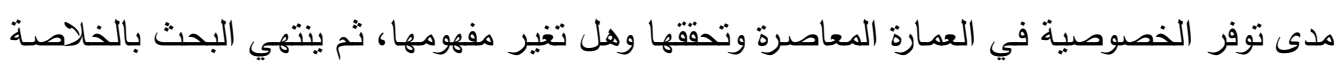
والتوصيات التي تخلص إلى أن هناك محددات يجب مراعاتها في العمارة لتحقيق الخصوصية. 


\section{1-1 - 1- مفهوم الخصوصية.}

عرفت الخصوصية على أنها من خاصة الثيء ، والخصوصية في اللغة تعني الانفراد أو الانحسار وهو

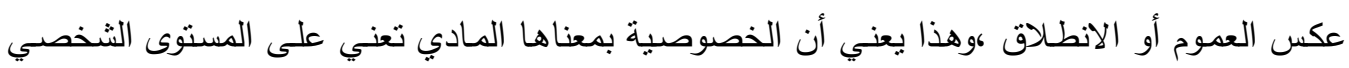

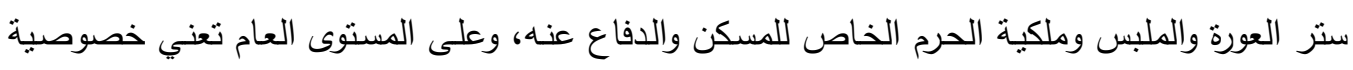

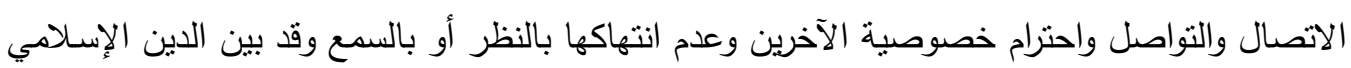
الكثير من المبادئ التي تحمي وتصون حرية الفرد وخصوصيته واحترام خصوصية الآخرين وحريتهم [ [ ].

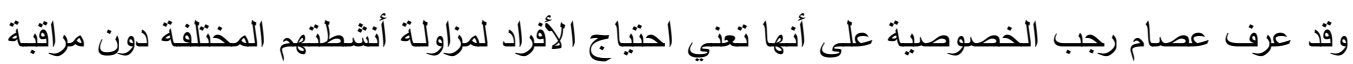

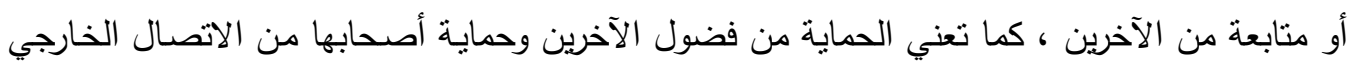

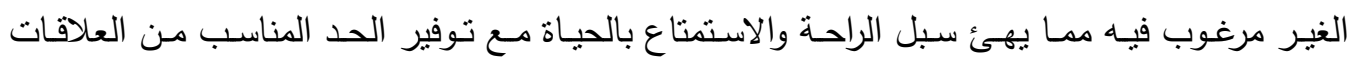
الاجتماعية والتعامل مع الآخرين [؟].

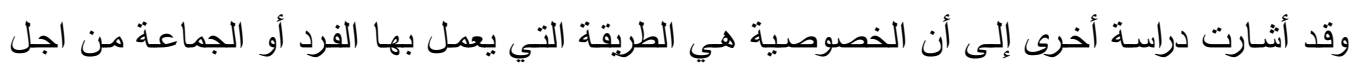

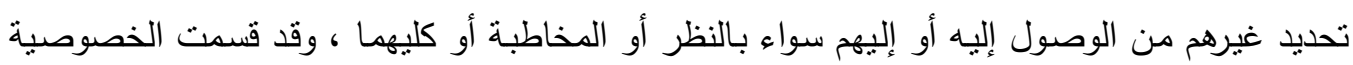

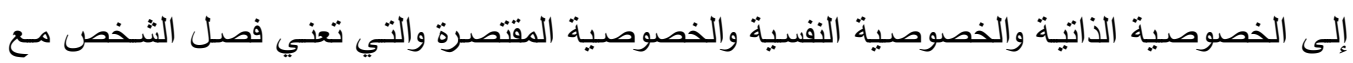
عائلته عن محيطه الاجتماعي وقد أكدت الثريعة الإسـامية هذه الرغبة مثل تحريم النظر إلى داخل منازل الآخرين[ب].

إن مفهوم الخصوصية يختلف في المجتمع الإسـامي عن المجتمع الغربي لأن الدين الإسـامي يعتبر

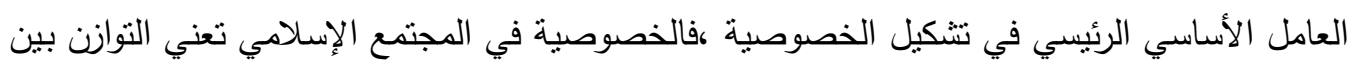

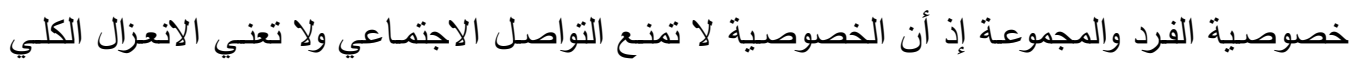

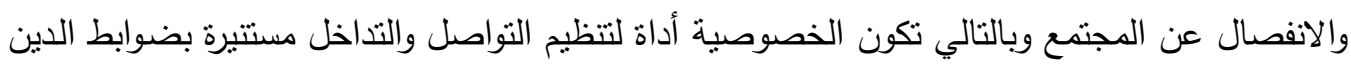
وسلوكيات المجتمع الذي يعيش فيه الفرد.

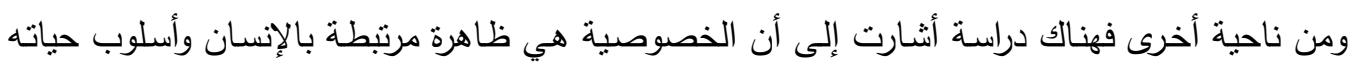

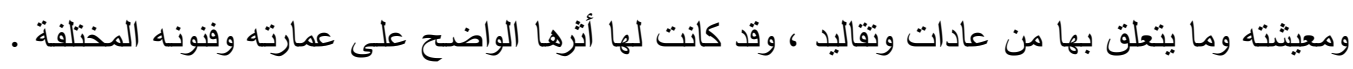

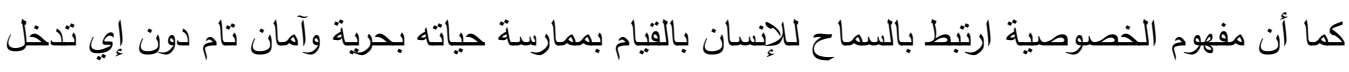

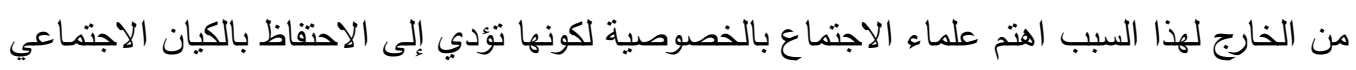

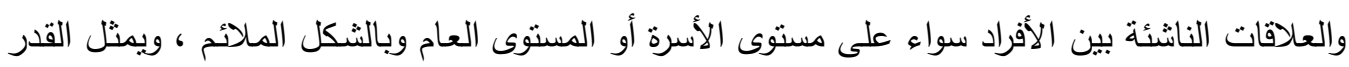

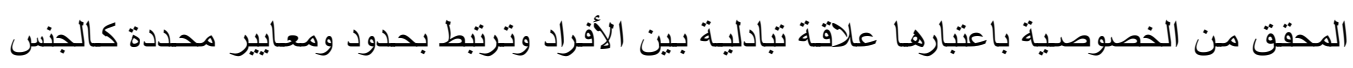

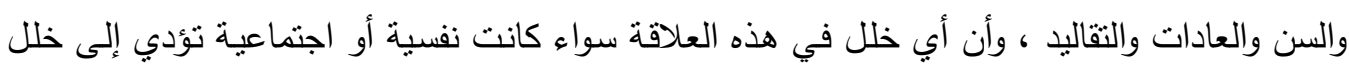

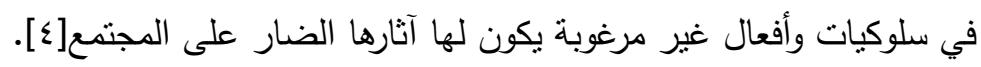


ويقصد بها النشاط الذي يتم وفئات الأفراد المؤثرين في الخصوصية.

أ- النشاط وعلاقته بالخصوصية

يمارس الإنسان أنواعا مختلفة من الأنشطة على المستوى العام والخاص وتتأثز طبيعة النشاط بدرجة

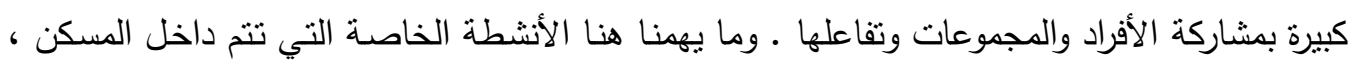

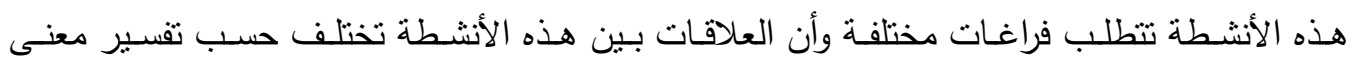

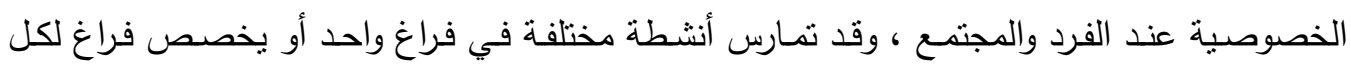

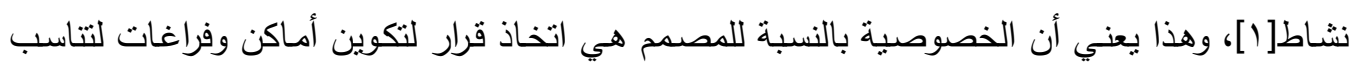
نثاط الفرد والمجموع وتعطيه الراحة - بصريا وسمعيا- ،وهذا يعني أيضا كفاءة التوجيه واحكام وتتظيم العلاقات والفراغات التي تتاسب الاستعمالات من حيث الحجم والوظيفة.

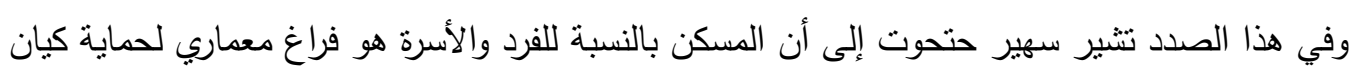

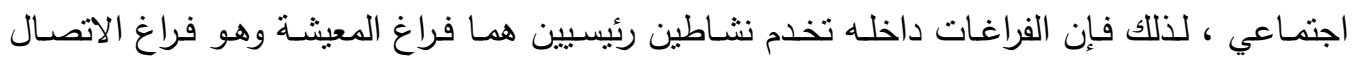

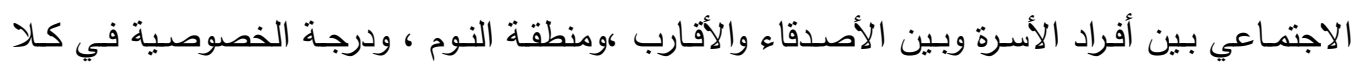

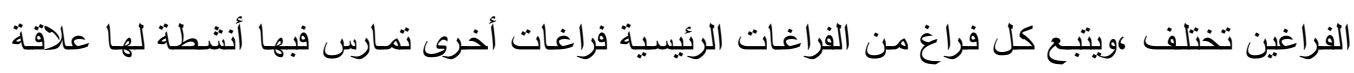
بالنشاط الرئيسي.وتخلص الباحثة إلى أن الخصوصية في الوحدة السكنية هي تعبير عن الكفاءة في الحركة والاستخدام مع الحفاظ على كيان اجتماعي قائم[ن].

ب- الأفراد وعلاقتهم بالخصوصية. ويقصد بهم الأثخاص التي تظهر الحاجة لعمل خصوصية لهم في المسكن ويمكن تقسيمه إلى فئات

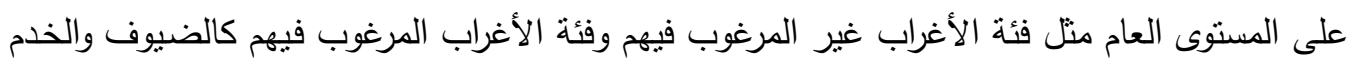

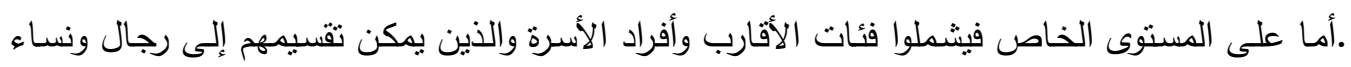

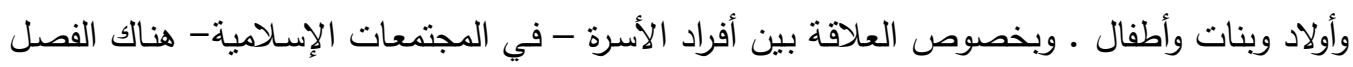

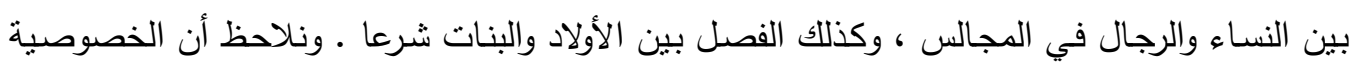

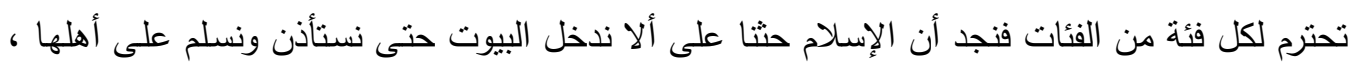

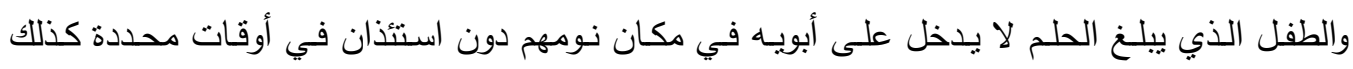

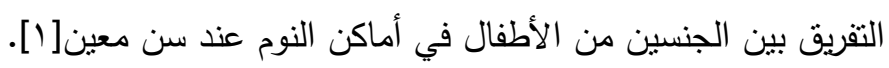

1-r- مستويات الخصوصية

تقسم مستويات الخصوصية إلى ثلاث مستويات هي الخصوصية على المستوى العام والخصوصية على المستوى شبه العام، والمستوى الخاص. 
أ- - الخصوصية على المستوى العام: تتشمل المناطق والفراغات ذات الاستعمال العام على مستوى

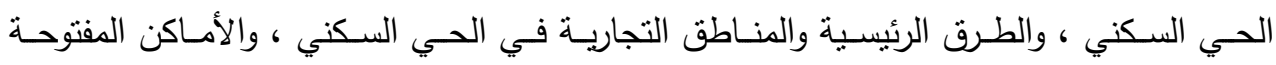

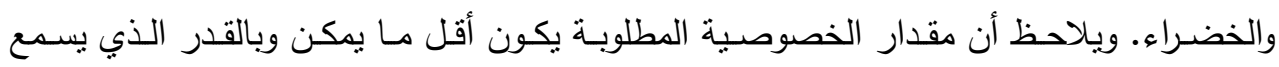

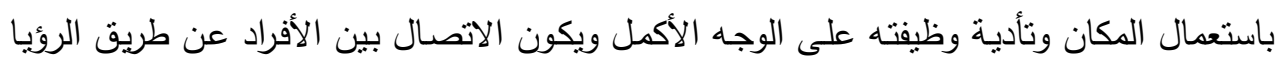
والسمع فقط [ـ]. ب- الخصوصية على المستوى شبه العام: وتتثمل المناطق والفراغات ذات الاستعمال العام على ولى

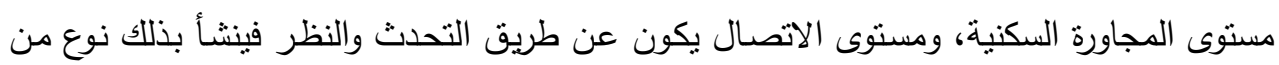
الألفة والمودة يعطي الإحساس بالتقارب الاجتماعي اللازم للتعايش في منطقة واحدة ، كما ينمي لإني

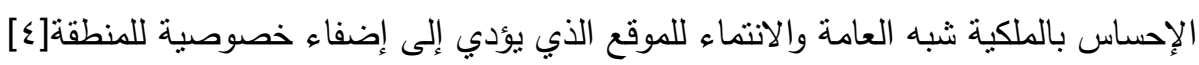

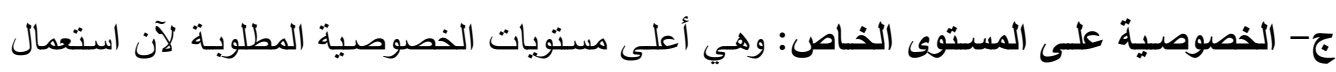

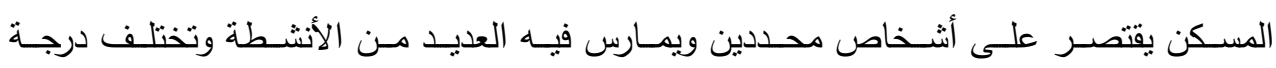

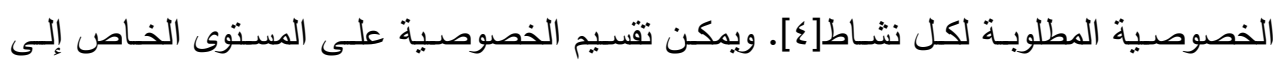

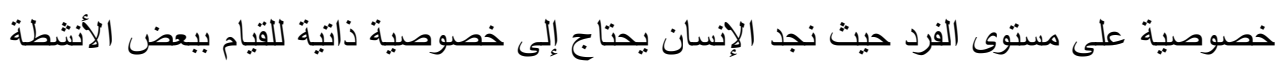

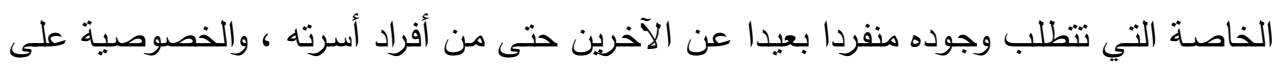

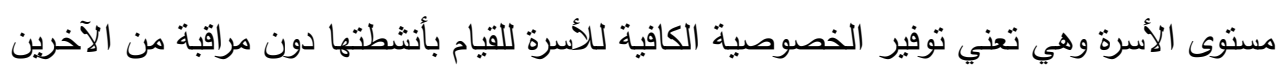

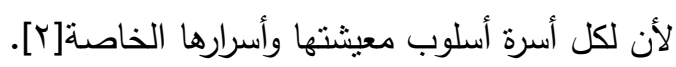

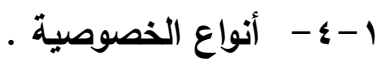

تتقسم الخصوصية إلى ثلاث أنواع هي الخصوصية البصرية ، والخصوصية السمعية ، والخصوصية

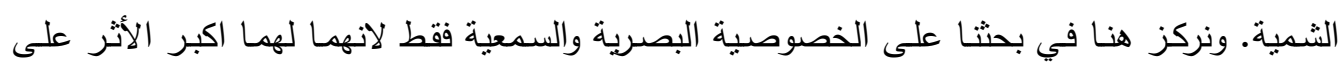
العمارة.

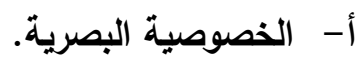

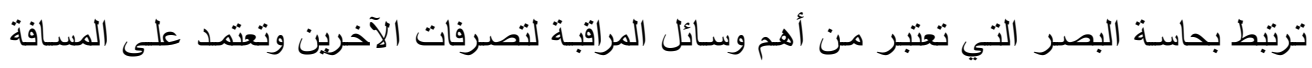

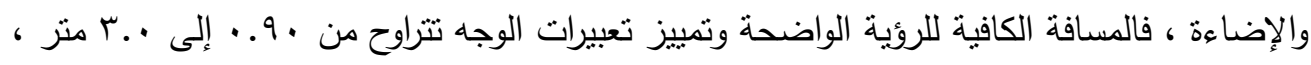

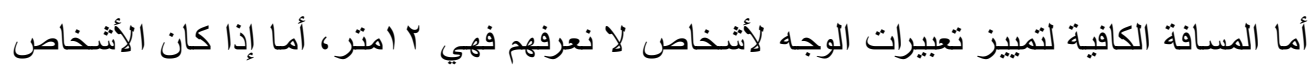

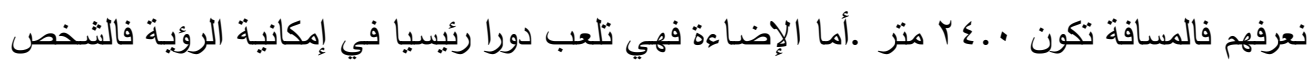

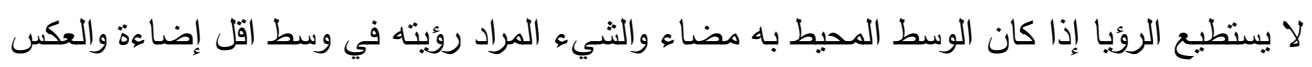

ويمكن توفير الخصوصية البصرية عن طريق اتباع الآتي [ج]: - تقليل الفتحات عددا ومساحة. 
- التوجيه للاخل بأن تفتح عناصر المسكن على فناء داخلي.

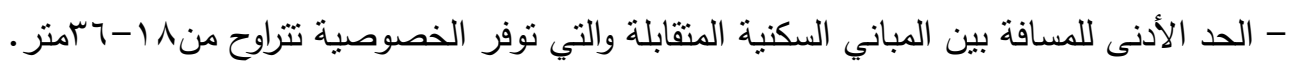

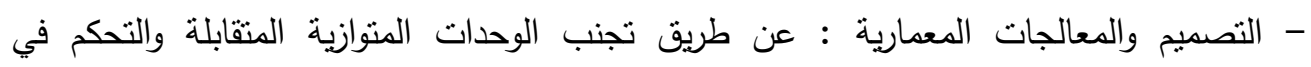

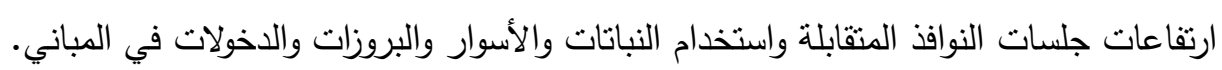

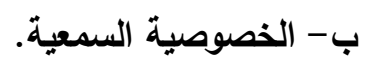
وهي تعني نوفير بيئة صوتية مناسبة سواء على مستوى المسكن أو خارجه تحقق القدر المطلوب من

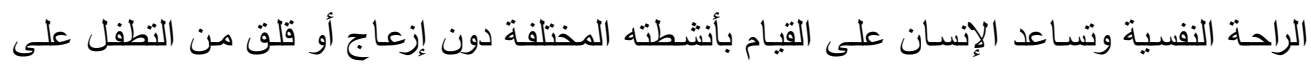
أحاديثه وعلاقاته داخل المسكن ، وتعني أيضا عدم انتقال الأصوات إلى الخارج أو إلى الداخل. الذان.

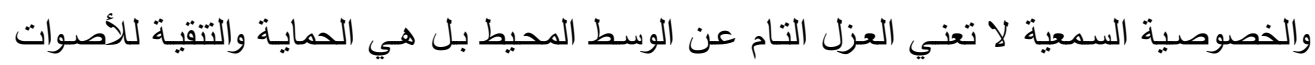

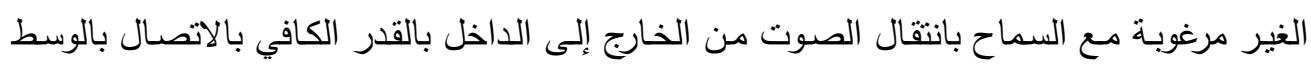

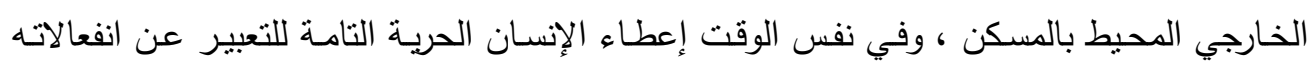

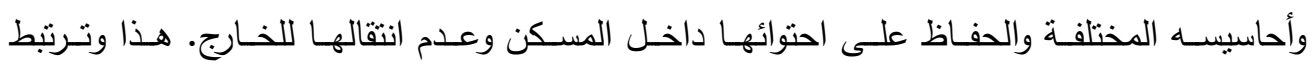
الخصوصية السمعية بدرجة كبيرة بمستوى الضوضاء الذي إذا زاد عن حد معين يسبب عدم القدرة على النوم، وما يترتب على ذلك من آثار صحية سيئة تمنا إلى المخ وتنبب عدم القدرة على التركيز

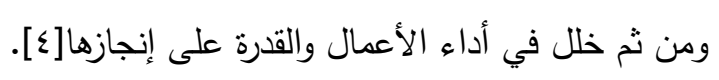

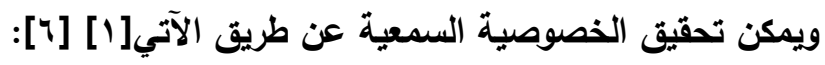

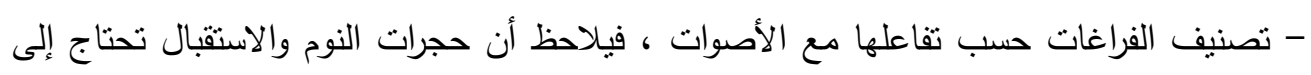

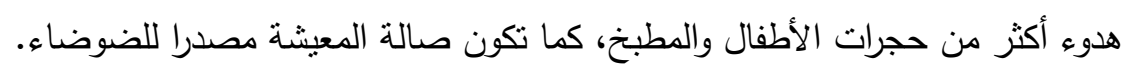
- استخدام عناصر مثل دواليب الملابس وارفف الكتب في عزل الأصوات بين الفراغات. - استخدام الحشوات والمواد العازلة للأصوات في داخل القواطيع والأبواب. - التوجيه للاخل باستخدام الأفنية الداخلية الخاصة. - نوجيه الوحدات السكنية بحيث تعطي ظهرها للضوضاء.

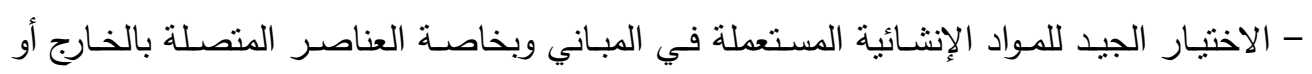
الفاصلة بين الوحدات المجاورة.

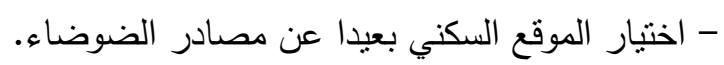

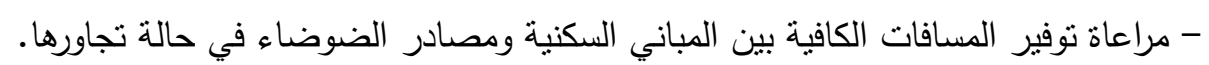

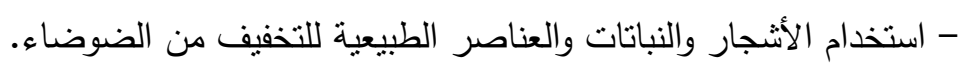




\section{r - الخصوصية في العمارة المعاصرة}

\section{r- - 1- مفهوم الخصوصية في العمارة.} أن مفهوم الخصوصية في العمارة يرتبط بمدى توفير الظروف الملائكسة للإنسان حتى يقوم بمنطلبات حياته اليومية في ظروف اجتماعية ونفسية ملائمة وبحرية تامة بدون تطفل الآخرين فيما يتعلق بحريته الثخصية،فالبنسبة لعمارة المسكن فالخصوصية تعني توفير الفراغات الدختلفة التي تحقق الاحتباجات والمنطلبات المعيشية المختلفة بحرية ومرونة فائقة مع توفير العزل سواء كان بصريا أو سمعيا ، ويتث ارتباط هذه الفراغات بواسطة مجموعة من عناصر الفصل والحركة محققة بذلك تسلسل منطقي للفراغات من العامية إلى الخاصية. وتختلف هذه الاحتياجات من مجتمع لآخر لأنها تتأثز بعوامل عديدة سواء كنت ثقافية ودينية واجتماعية

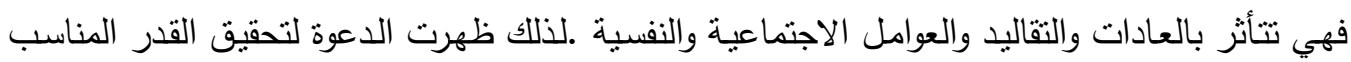
من الخصوصية في العمارة المعاصرة التي تلبي الاحتياجات المطلوبة وذلك عن طريق التصميم الملائم "لاستيعاب تلك الاحتياجات

وهنا يجب أن يلاحظ أن تحقيق الخصوصية في العمارة لا يعني الفصل التام والعزلة الكاملة للإنسان

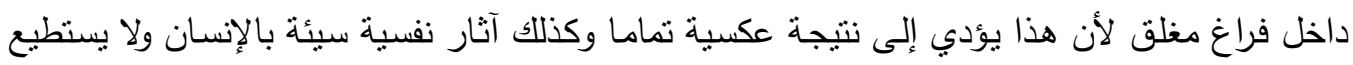

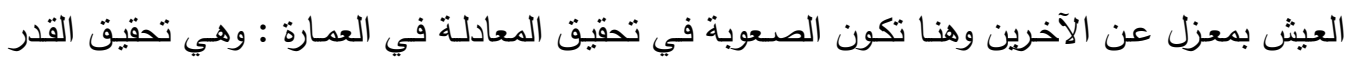
المطلوب مـن الخصوصية الذي يحقق العزل المطلوب وكذللك الاتصـال المعقول بالعناصـر البيائيـة

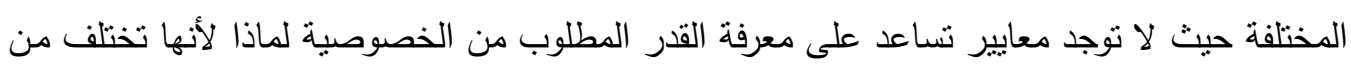
شخص لآخر [ع].

r-r - العوامل المؤثرة على الخصوصية في العمارة r-r- - ا- العوامل التي أثرت على مفهوم الخصوصية في الماضي إن العوامل التي أثرت على مفهوم الخصوصية في الماضي هي التعاليم والمبادئ النابعة من القرآن

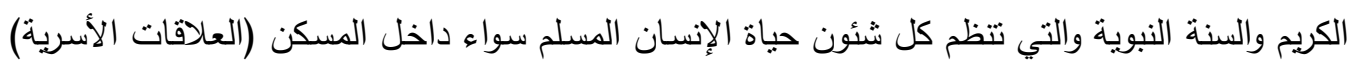

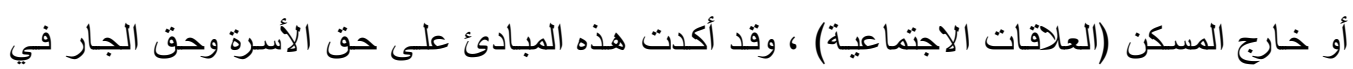

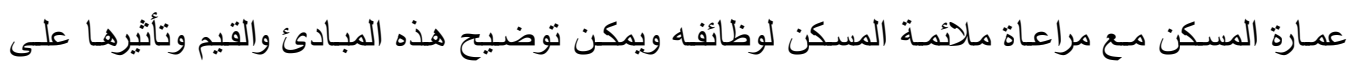
الخصوصية فيما يلي: 
* ففي مجال حق الأسرة أعطى الإسلام أهمية خاصة لأنها تمثل المجتمع الإسلامي الأصغر ونواة

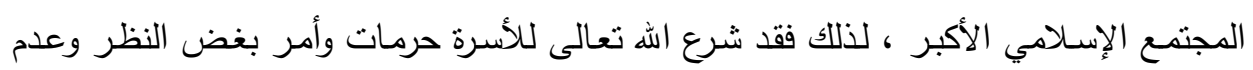

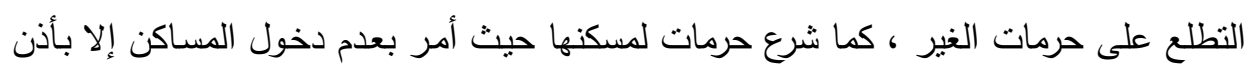

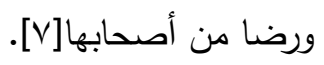

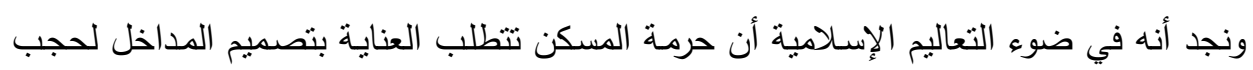

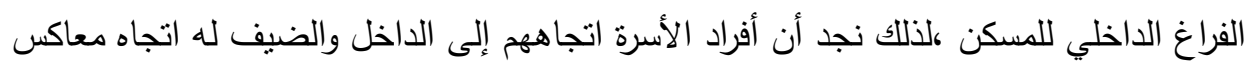
كمبدأ لتحقيق خصوصية المسكن على أن خصوصية المسكن لم تراعى فقط بالنسبة للداخل ولكن أيضا روعيت بالنسبة للخارج حيث روعي طريقة تصميم الفتحات الخارجية ومعالجتها.

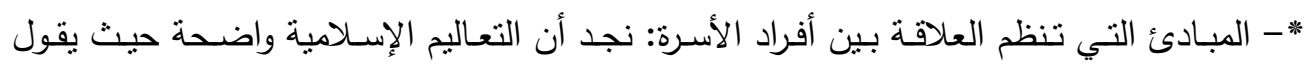

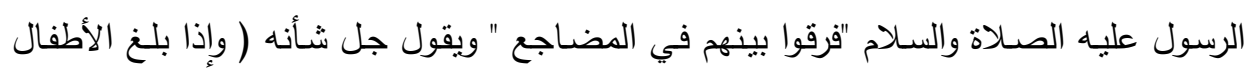

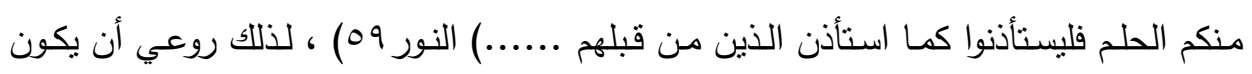

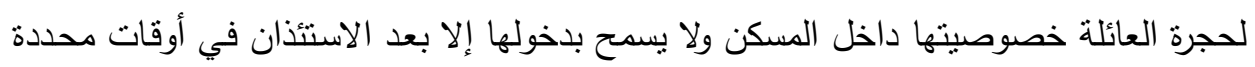

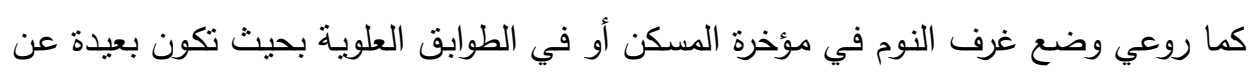

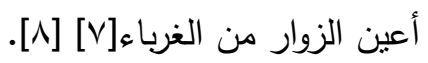

* مراعـاة حق الجـار : أعطت التعـاليم الإسـلامية أهميـة كبيرة للجـار حيث قال رسـول الله عليه

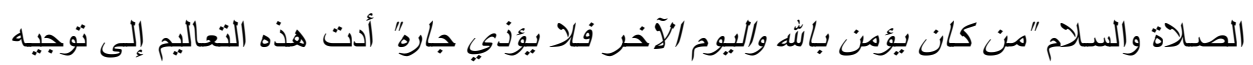

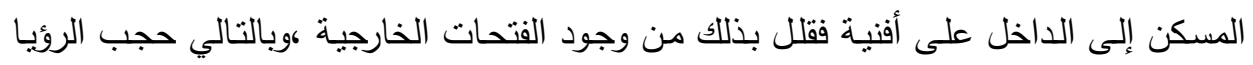

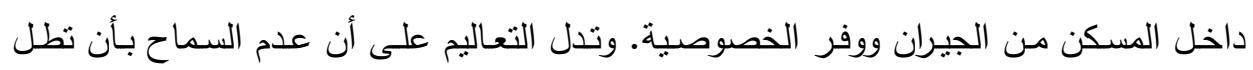

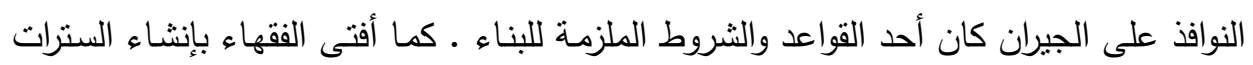

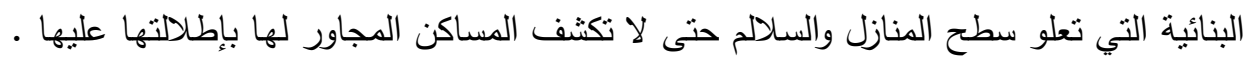
لذلك كان عدم تقابل فتحات المساكن المطلة على الثوارع والطرقات سمة معمارية تطبيقا لاحكام

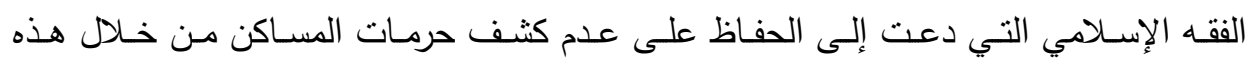
المداخل[ن].

* حجاب المرأة : لقد حض الإسـام على حجب النساء داخل المسكن من أعين الغرباء من زوار المسكن ومن الجيران لذلك انعكس ذلك على تصميم المسكن وظهر بوضوح في توجيه المسكن

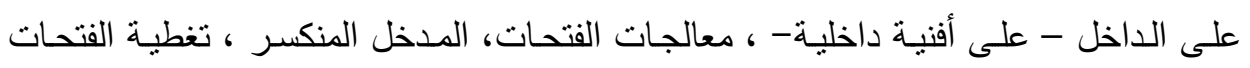

$$
\text { بمشربيات[ • [1]. }
$$

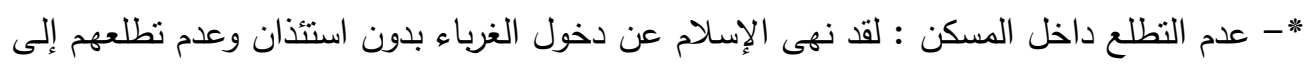

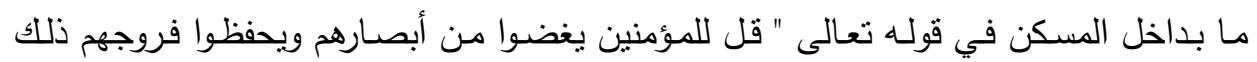


أزكى لهم إن اله خبير بمـا يصنعون " (سورة النور /•r ) ، وقد انعكست هذه التعاليم على إعلى

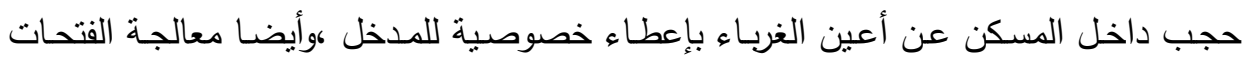
الخارجية[V].

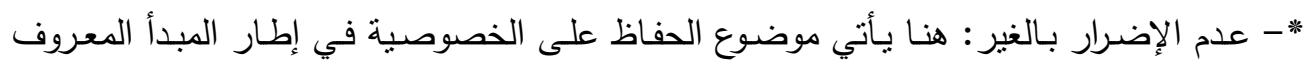

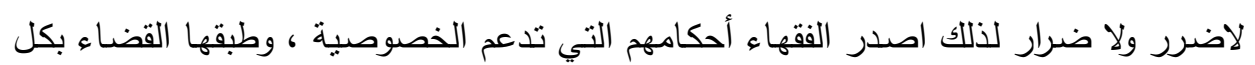

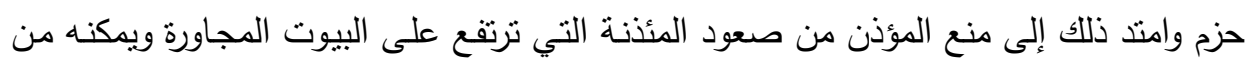

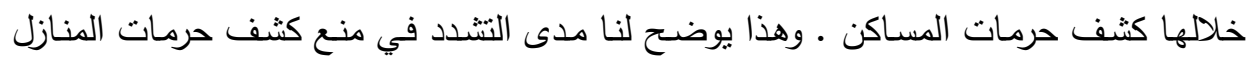
والحفاظ على خصوصيتها [9].

r-r-r - العوامل التي أثرت على مفهوم الخصوصية في العمارة المعاصرة

هناك العديد من العوامل التي أثرت على فقدان الخصوصية في عمارة المسكن المعاصر وفي العمارة

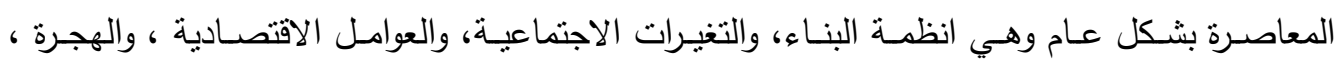
والعوامل التقافية، والعوامل التكنولوجيا ، والعوامل السياسية. ويمكن توضيح هذه العوامل فيما يلي: أ- أنظمة البناء تعتبر أنظمة البناء من الأفكار المستوردة التي وردت إلى مصر وتم تطبيقها في الددن الجديدة وعلى إنى المدن القديمة، وكان لهذه القوانين آثار سيئة على عمارة المسكن سواء من ناحية الثكل أو الوظيفة ولثية

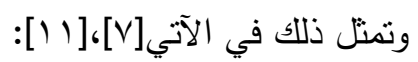
* - أعطت هذه القوانين المباني اكبر عدد من الواجهات.

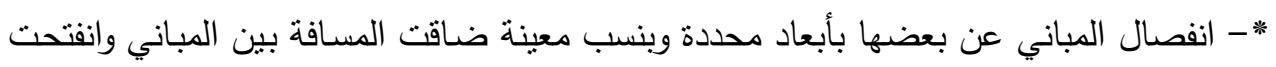
على الخارج. * - نساوت أبعاد القطع - تقريبا- ونسب الردود والارتفاعات وبالتالي تثابهت التصميمات.

ومن خلال دراسة تلك الأنظمة يلاحظ أن هناك قصورا في مراعاة ملائكة المباني السكنية لاستيعاب الاحتباجات الضرورية - منل الخصوصية-، فلم تتعرض أنظمة المباني لتحديد أماكن الفتحات بحيث

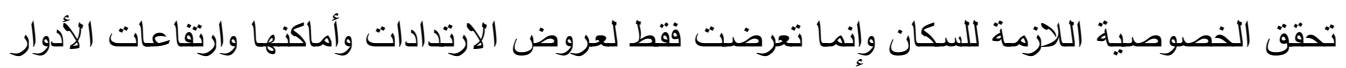

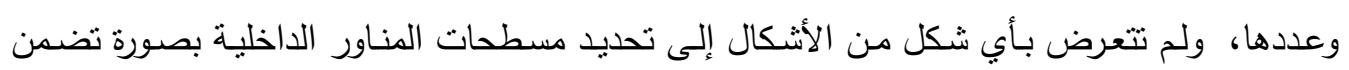
تحقيق الخصوصية السمعية ،وعدد الوحدات التي يمكن أن تشترك في عناصر التحري الحركة الرأسية والأفقية 
ب- نمط البناء المستخدم

تتعدد الأنماط التي يمكن من خلالها تصنيف البناء على أساسه طبقا لمجموعة من الاعتبارات فيما

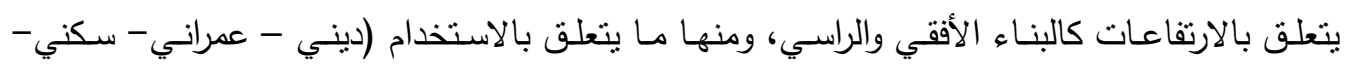

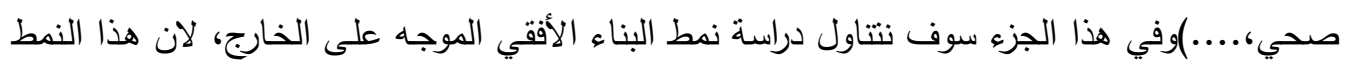
هو النمط المسيطر والسائد في أحياء مدينة جده، وقد لوحظ من خلال دراسة هذا النمط الآتي:

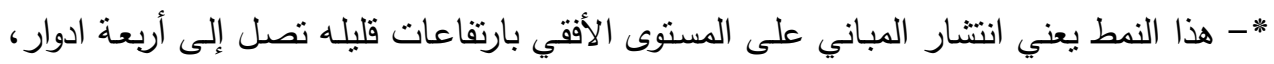

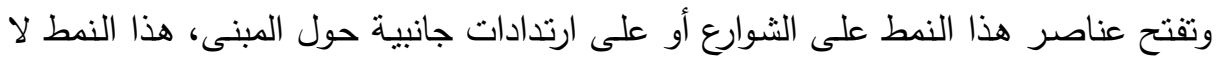

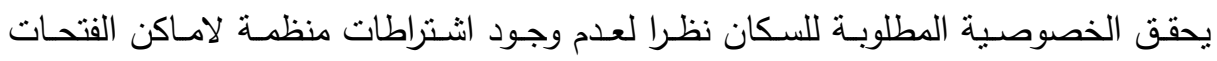
الخارجيـة والبروزات فادى ذلك إلى جرح خصوصية المساكن ، ولتحقيق الخصوصية يلجأ

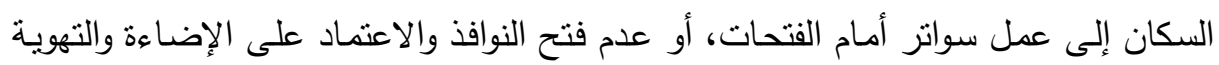

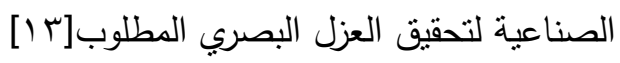

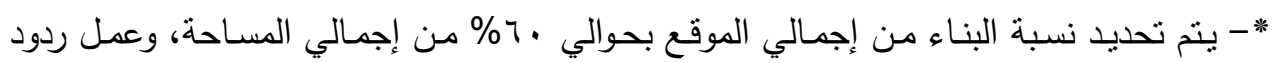

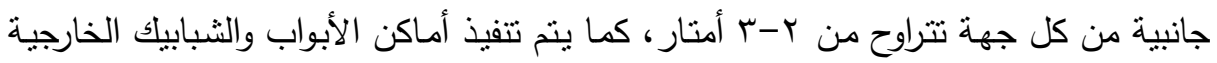

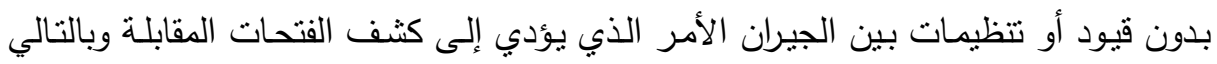

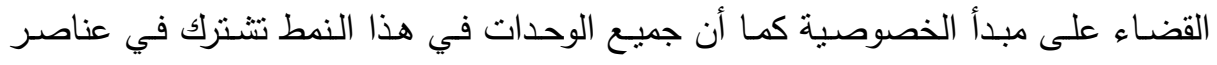

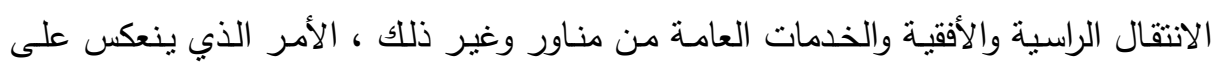

$$
\text { الخصوصية ويقضي عليها [ـ 1] }
$$

* - هذا النمط لا يساعد على إيجاد العلاقات الإنسانية المتأصلة للمجتمع، وبذلك فقدت الصلات

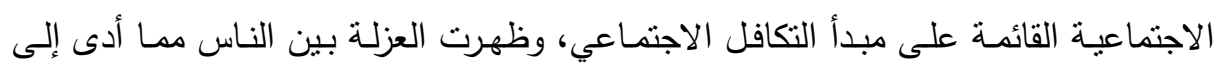

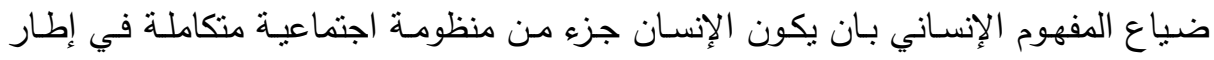

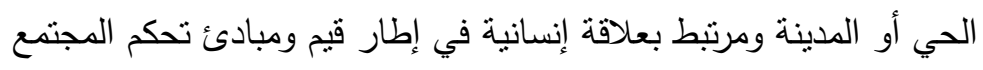

\section{ج- التغيرات الاجتماعية}

يقصد بالتغير الاجتماعي بأنه التحول الطبيعي الذي يصيب أنماط العلاقات وشكل السلوك السائد بين

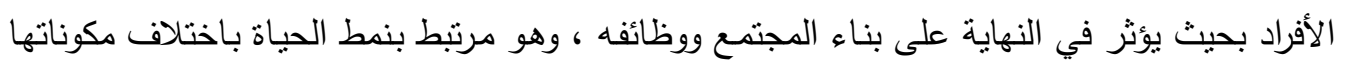

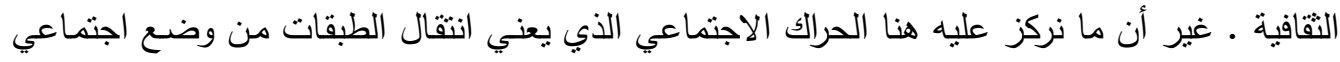

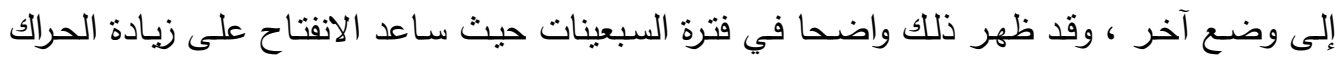

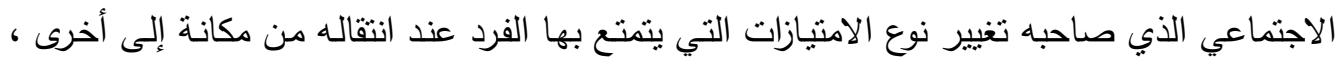

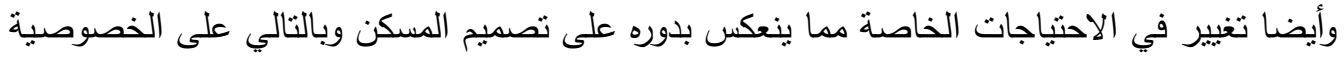
المطلوبة فيه [10] 


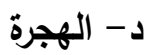

أدي ثركيز النشاطات الاقتصادية وزيادة الخدمات في المدينة ، وفي نفس الوقت قلة الموارد الطبيعية

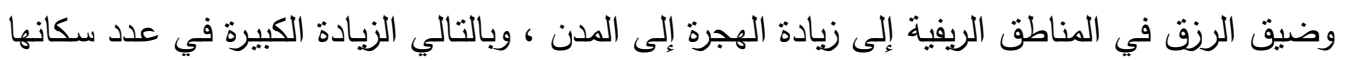

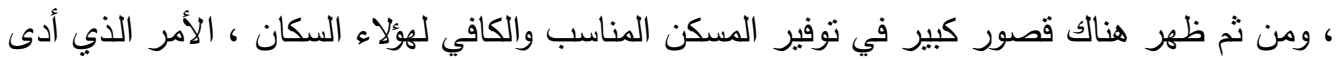

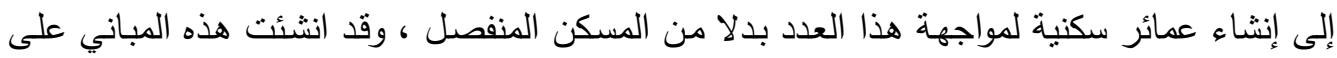
نظام تقسيم شبكي وقام بتصميم تلك المباني أفراد غير مؤهلين - في بعض الاحيان-، وكانت النتيجة أن هذه العمائر تكثف بعضها البعض كثفا كاملا مما اضطر ببعض السكان لاتخاذ تدابير مختلفة

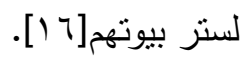

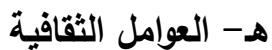

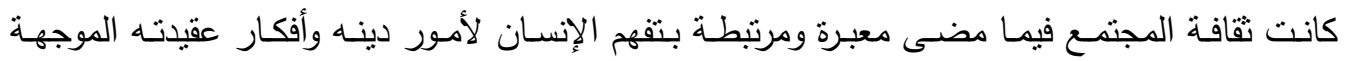

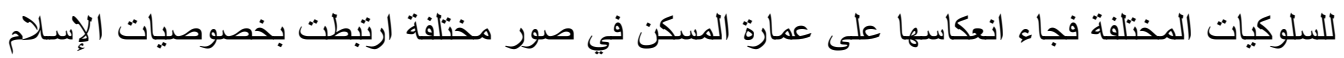

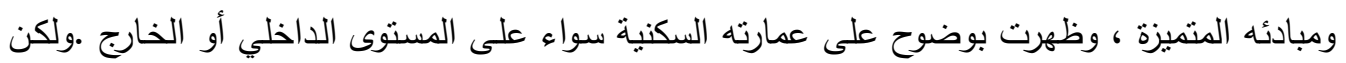

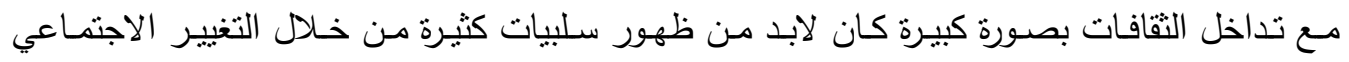

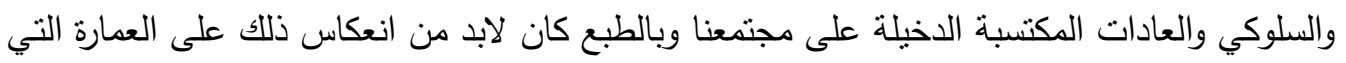

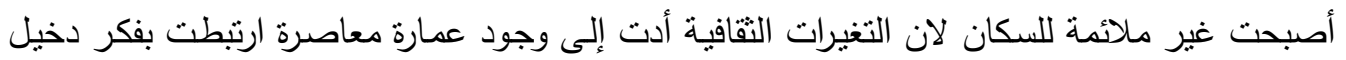

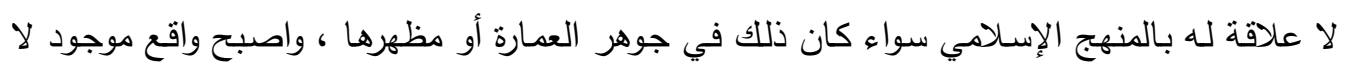
بمكن تغييره لأنه أصبح الهيكل العمراني لكافة المدن والقرى على كافة مستويات الإنكان المختلفة. و - العوامل التكنولوجيا أثز التقدم العلمي في الصناعات المختلفة والتي كان لها دور كبير في تطوير طرق وأساليب الإنشاء المختلفة التي أدت إلى تغيير وجه المدينة ، وشجعت أنماط جديدة من البناء بارتفاعات عالية ، وأثنكال منباينة واختل التوازن بين الكتل المعمارية ، وتغيير شكل المدينة وظهرت المباني ذات الفتحات الواسعة

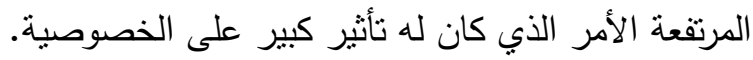

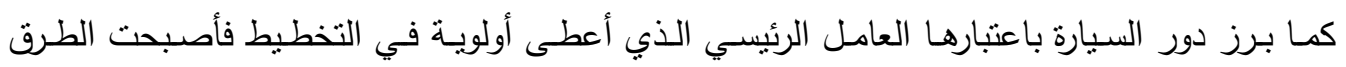

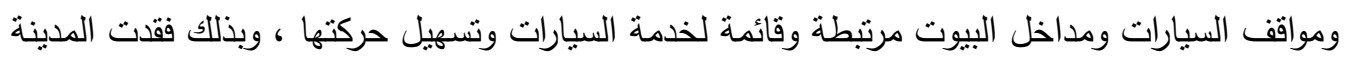

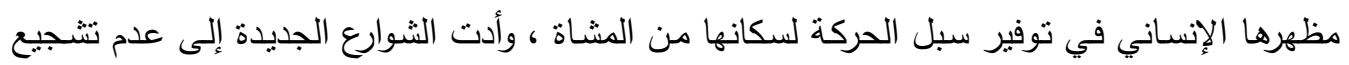

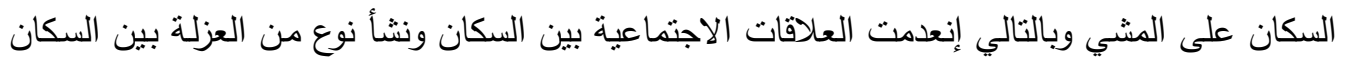

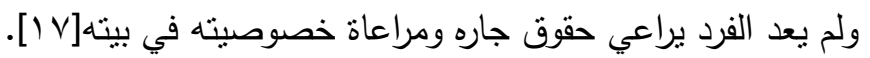




\section{ب- دراسة الخصوصية في العمارة المعاصرة}

من خلال استقراء الوضع الحالي للعمارة المعاصرة في مدينة جده ومن خلال الزيارات الميدانية للأحياء السكنية بالمدينة تبين أن هناك أزمة خصوصية في أحياء المدينة وقد وصل الأمر إلى أن قامت أمانة المانة

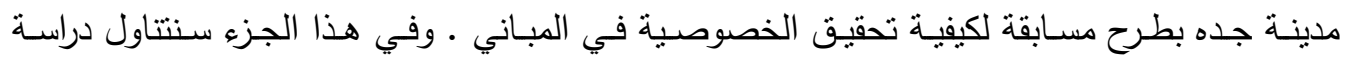
الخصوصية في المدينة التقلبدية كمقدمه ، ثم دراسة الخصوصية في العمارة المعاصرة ب- الخصوصية في العمارة التقليدية تميز النسيج العمراني التقليدي في مدينة جده بالكتل المعمارية المترابطة والمنصلة ببعضها البعض،

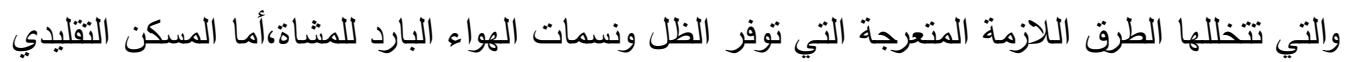

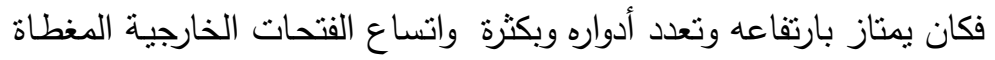

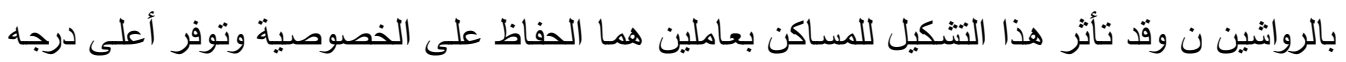

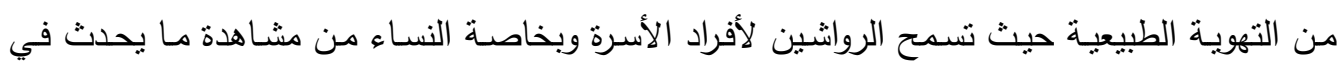

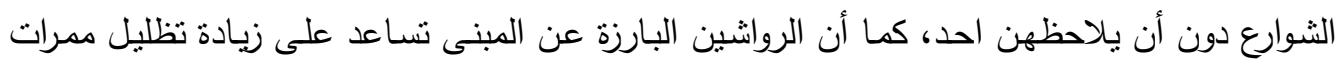

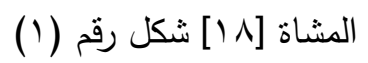
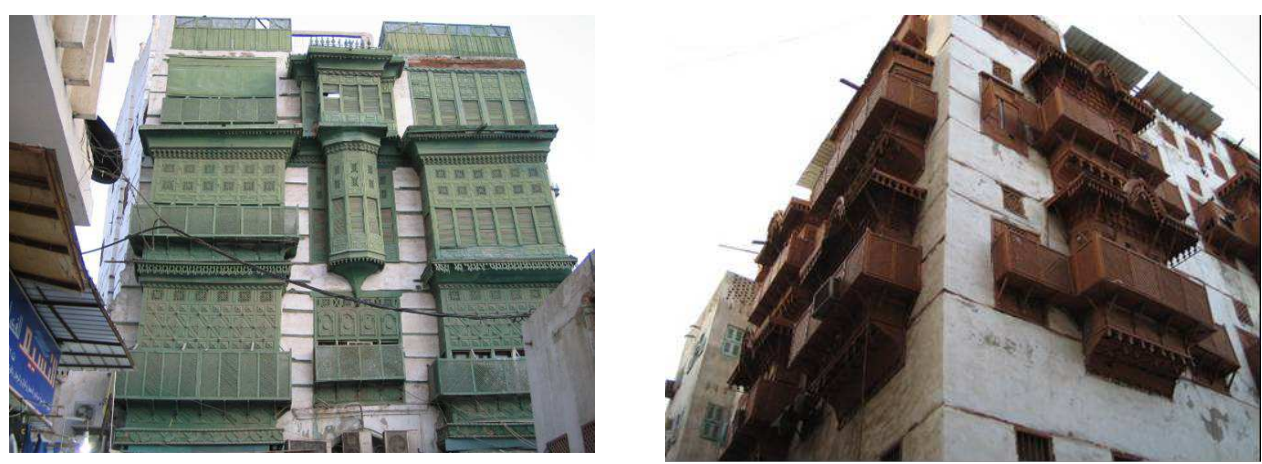

شكل رقم (1) العمارة التقليدية في مدينـة جده ويظهر كيفيـه تحقيق الخصوصية

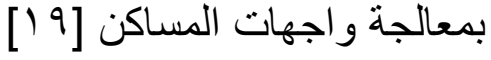

r-r - الخصوصية في العمارة المعاصرة

أدت أنظمة البناء المستخدمة إلى توجيه المباني على الخارج فانعدمت الخصوصية الخارجية ، كما كما أن

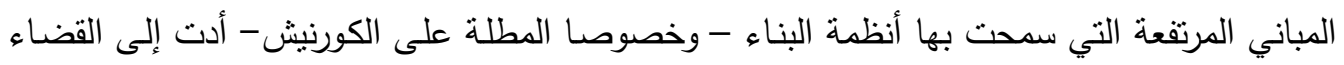

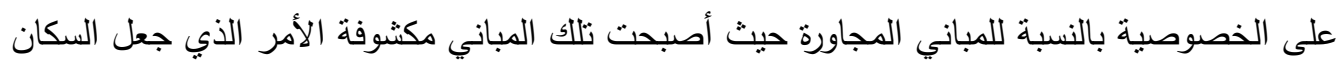

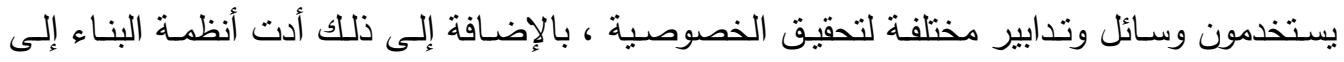
الآتي:- بانغ

" استخدام الفتحات الكبيرة مع الانفتاح على الخارج ساعد في القضاء على الخصوصية . 
* نتيجـة لتوجيـه المسكن على الخـارج أصبحت المسـاكن تطل على بعضـها ، أو على الثـوارع المزدحمة بوسائل النقل ففقدت الخصوصية السمعية والمطل الطبيعي الذي كان على الفناء الداخلي.

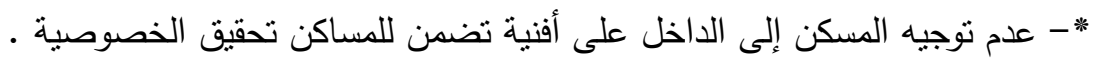

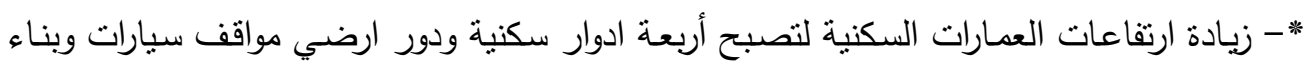

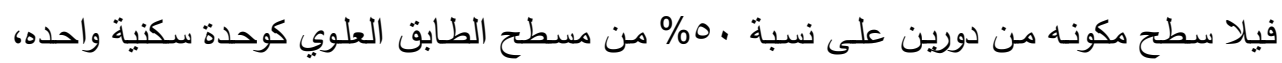

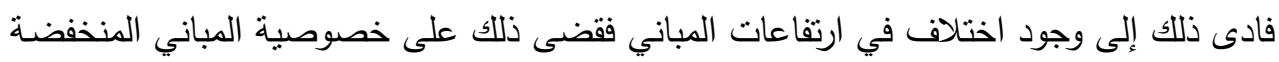

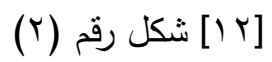
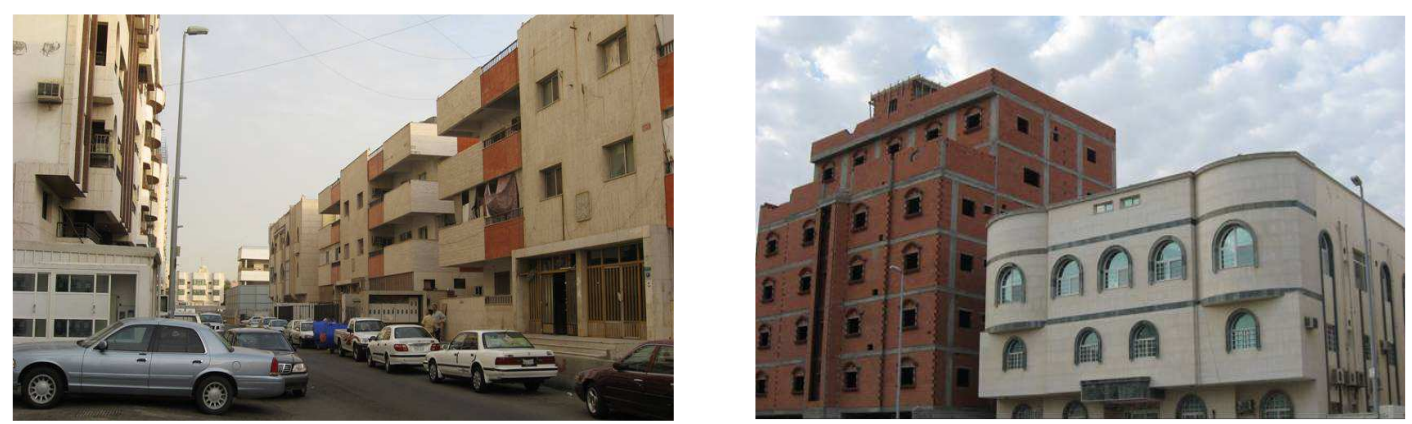

شكل رقم (Y) اختلاف ارتفاعات المباني نتيجة لأنظمة البناء المستخدمة مما أدى إلى القضاء

$$
\text { على الخصوصية[ (19]. }
$$

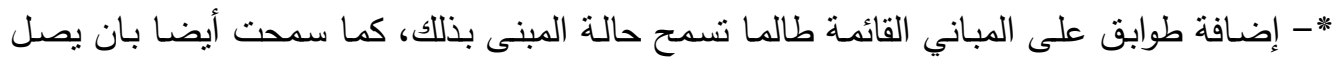

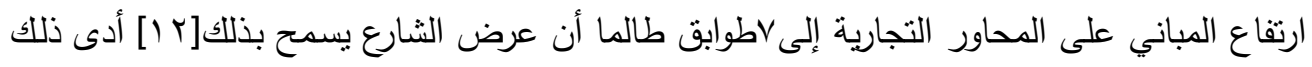

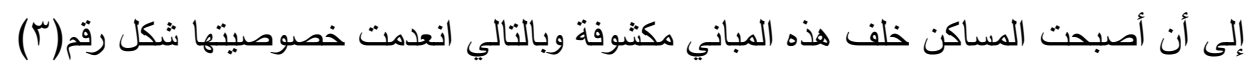
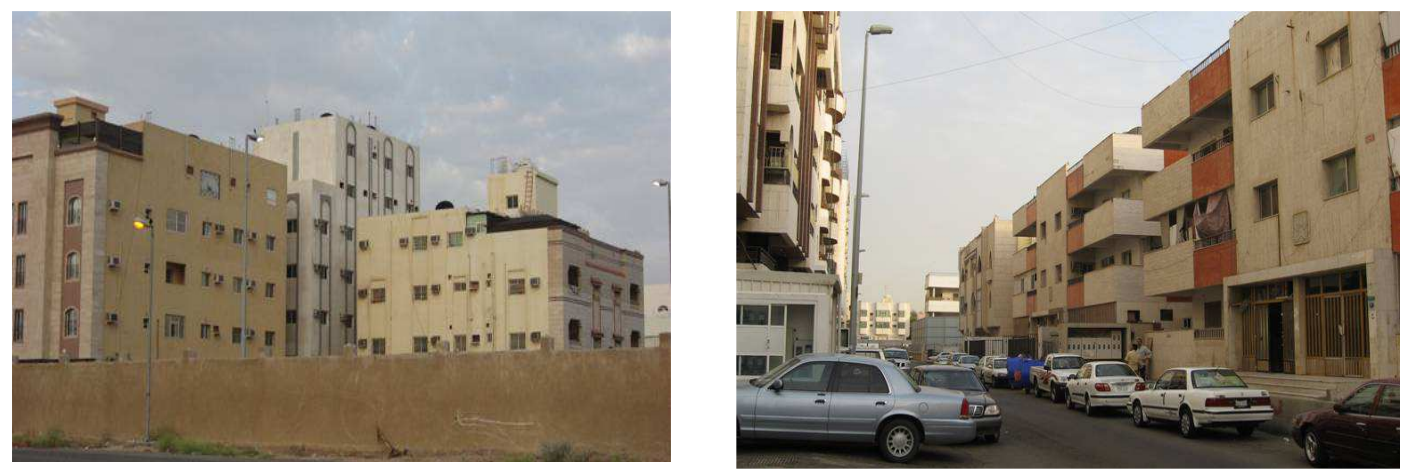

شكل رقم (ץ) زيادة ارتفاعات المباني على المحاور التجارية أدى على القضاء على خصوصية المباني الخلفية 
* عمل ارتدادات لا يقل عن r متر للارتفاعات من طابق على ثلاث طوابق، وبارتدادات r متر

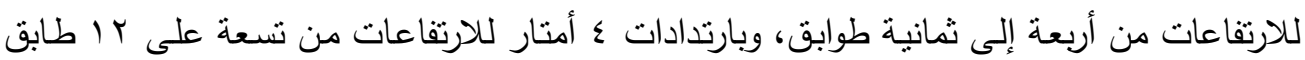

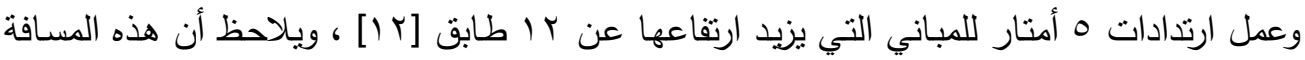

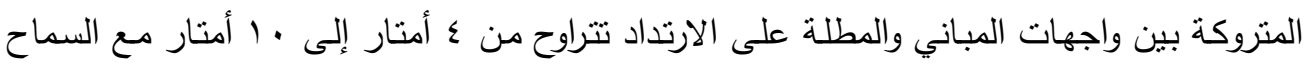

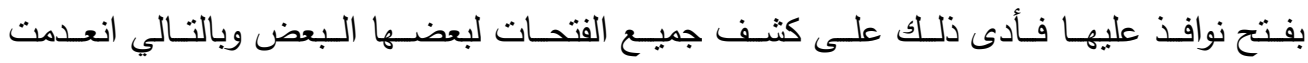
الخصوصية[r 1 [ شكل رقم (؟).
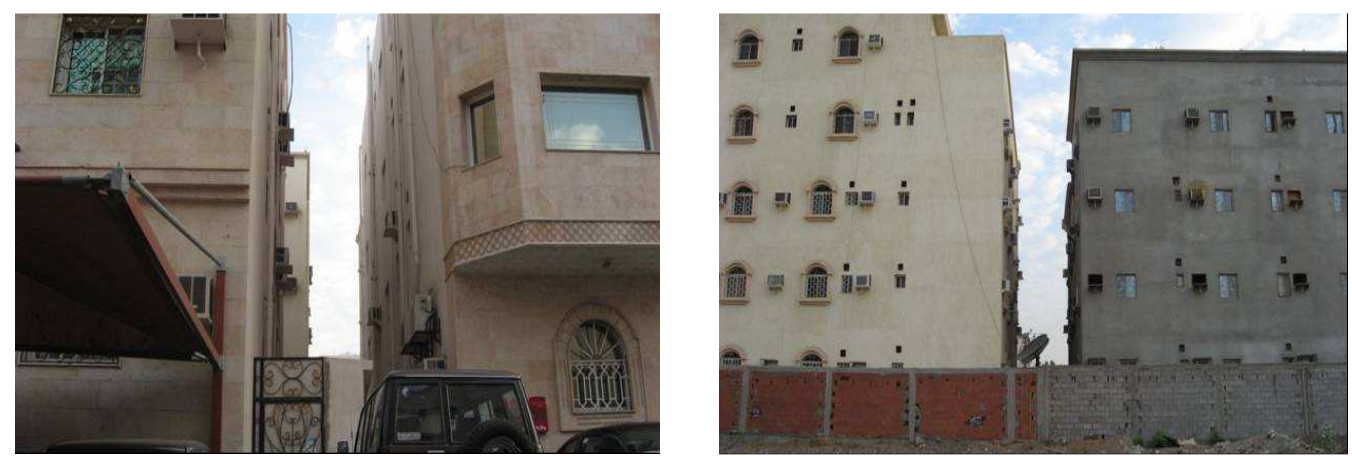

شكل رقم (ع) الارتدادات بين المباني ويلاحظ أن المسافة بين الفتحات لا تحقق الخصوصية[9 19]

r-r- الأساليب المستخدمة لتحقيق الخصوصية

تتوعت الأساليب التي استخدمها السكان في تحقيق الخصوصية الخارجية كما يلي:* - استخدام ألواح صاج مموجة أعلى المبنى لتحقيق الخصوصية للسطح شكل رقم (0-أ)، وأيضا استخدام نفس الأسلوب أعلى السور وبارتفاع كامل البيت لتحقيق الخصوصية في الواجهات

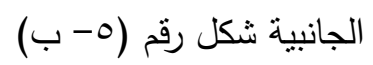

* - معالجة الفتحات الخارجية بوضع ستائر معدنية عليها شكل رقم (0- (- ج)

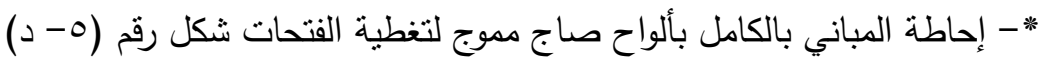

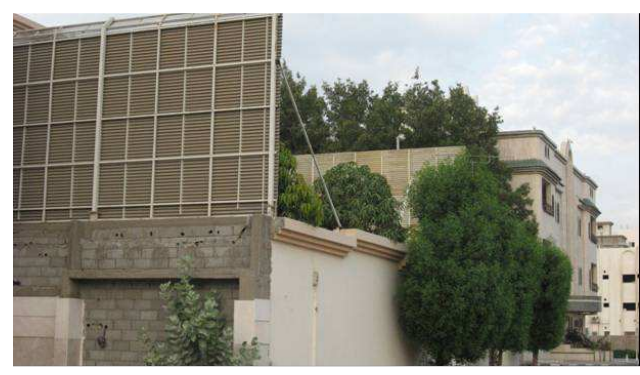

ب- استخدام ألكواح صـاج مموج أعلى بارتفاع المسكن

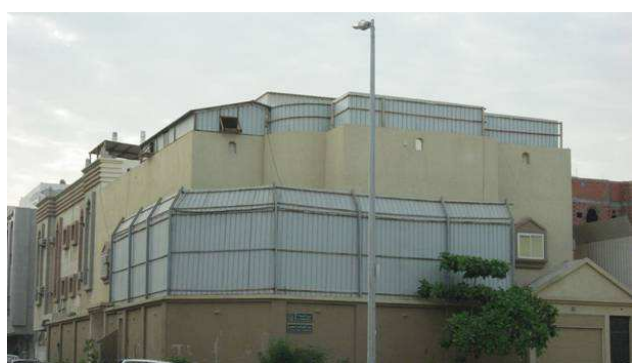

أ- استخدام ألـواح صـاج ممـوج أعلى السطح السور 

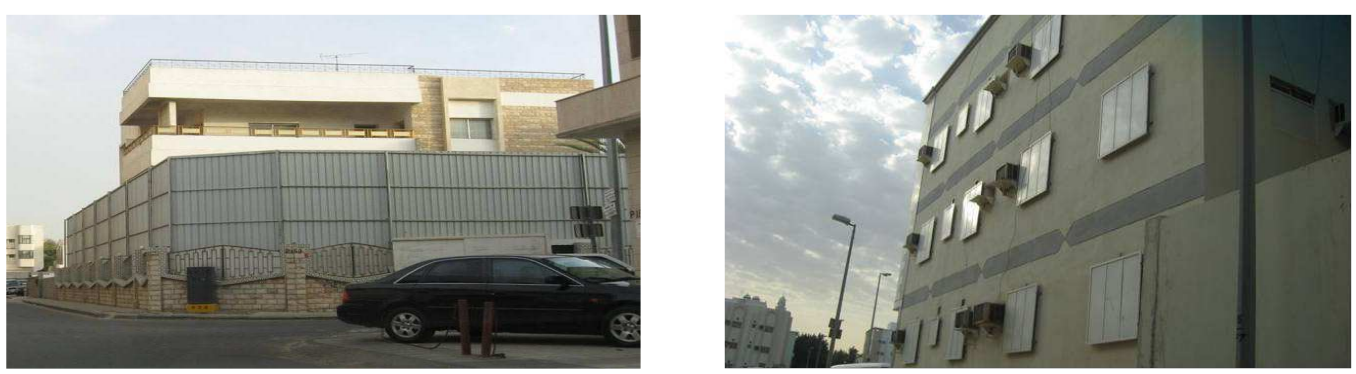

ج- معالجة الفتحات بوضع ستائر عليها د د إحاطة المبنى بألواح صاج لتغطية الفتحات

شكل رقم (0) الأساليب المستخدمة لتحقيق الخصوصية[19]

\section{الخلاصة والتوصيات}

نخلص من الدراسة أن مفهوم الخصوصية يعني الاتصال والتواصل واحترام خصوصية الآخرين وعدم

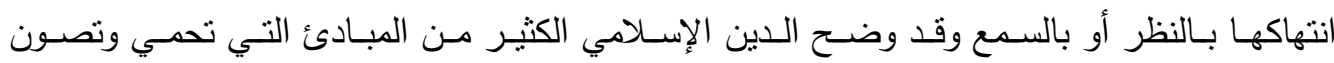

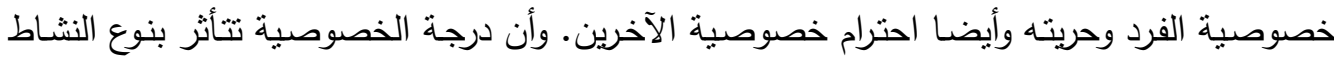
الذي يمارس وكذلك الأفراد الذين يمارسون هذه الأنشطة.

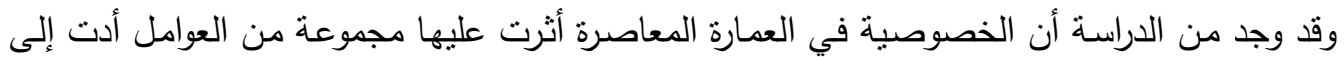

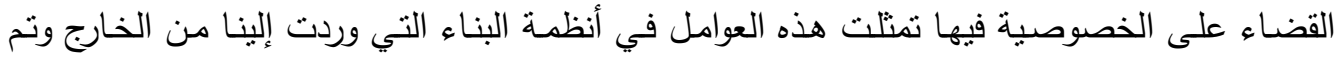
تطبيقها في المدن، مما كان لها آنار سيئة على عمارة المسكن وأظهرت القصور الثنديد في ملائمة تلك فئك

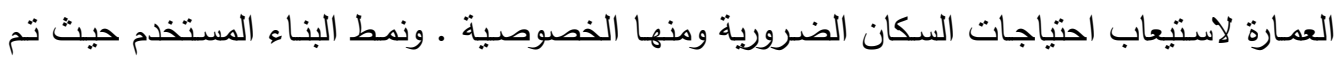

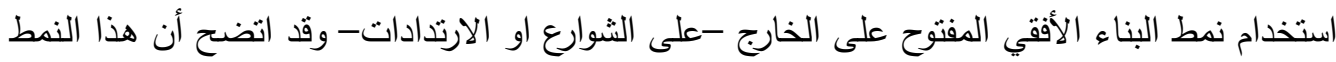

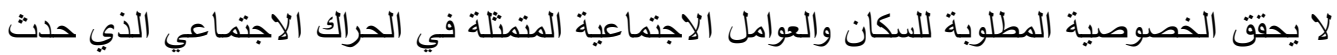
والطبقات التي برزت وتلبية احتياجاتها السكنية .والهجرة التي أدت إلى زيادة سكان المدن زيادة كبيرة والقصور الثديد الذي ظهر لتوفير المسكن المناسب والكافي لهؤلاء السكان فظهرت مناطق الإسكان

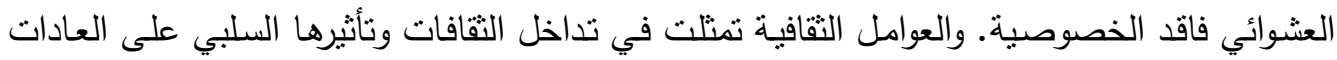
والسلوك وانعكاس ذلك على العمارة ـ والعوامل التكنولوجيا التي ظهرت في أسـاليب ومـواد الإنثـاء

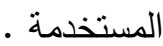

وقد أثرت تلك العوامل على مفهوم الخصوصية في العمارة المعاصرة وأدت إلى تغيير المفاهيم التي كانت مرنبطة بالدين إلى مفاهيم مستوردة بعيدة عن الدين ، واصبح هدف كل فرد هو إبراز مبناه

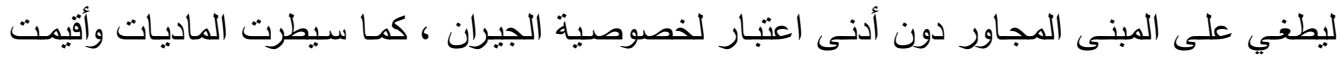
المشروعات من واقع جدواها الاقتصادي بحيث تحقق أكبر عائد مادي دون مراعاة أب اعتبار آخر - 
تحقيق الخصوصية - فادى ذلك إلى ظهور موجة الأبراج العالية التي انتشرت في المدن التي قضت

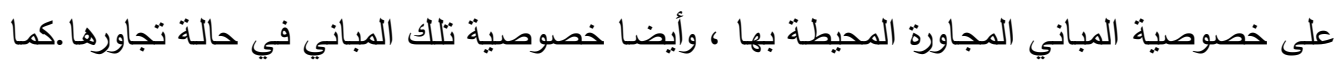

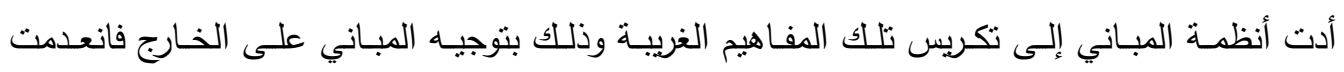
الخصوصية البصرية وأيضا السمعية مع تقليل اسماك الحوائط.

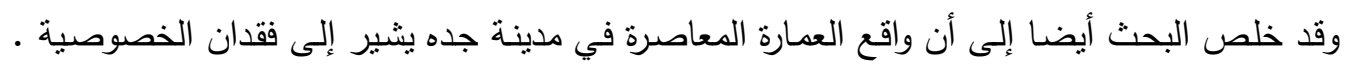

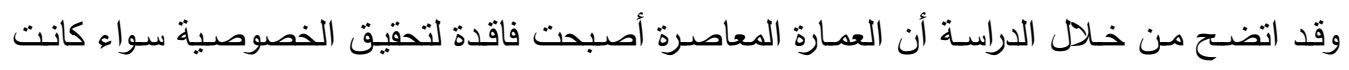
بصرية أو سمعية، وأنه لتحقيق ذلك يلزم مراعاة واتباع التوصيات الآتية:

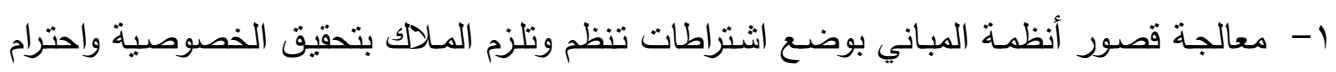

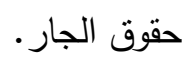

r- العمل على توجيه العمارة على الداخل على أفنية داخلية بدلا من توجيهها وانفتاحها على الخارج. r- مراعاة أماكن الفتحات المطلة على المناور الداخلية بحيث تحقق الخصوصية للوحدات السكنية.

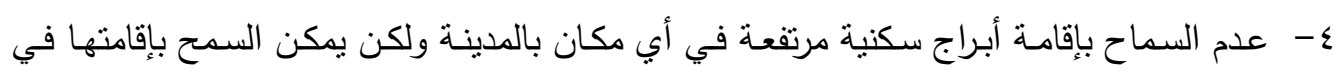
أماكن محددة. ه- الاهتمام بتوعية المصممين بأهمية مراعاة تحقيق الخصوصية الداخلية والخارجية للمستخدمين في تصميماتهم.

\section{المراجع}

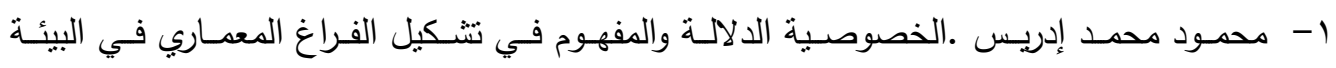

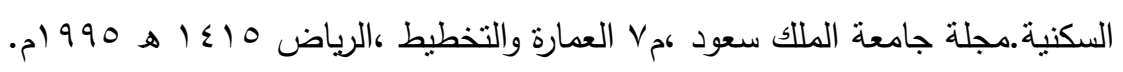
r- عصام رجب إسماعيل .مفهوم الخصوصية وتأثيره علي تصميم السكن في مصر .كلية الهندسة

$$
\text { قسم العمارة ، جامعة أسيوط ـ } 99 \text { ام. }
$$

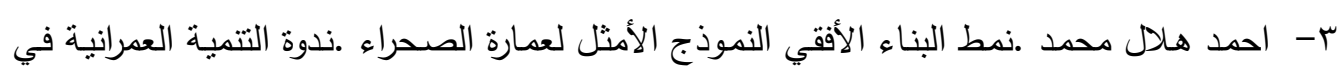

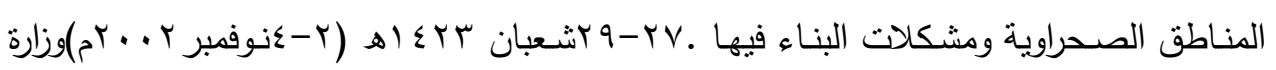

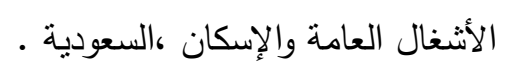

ع - ايمن علي .القيم الإسلامية كمدخل لتحقيق الخصوصية في البيئة السكنية المعاصرة .قسم العمارة

$$
\text { كلية الهنسة جامعة أسيوط بو } 99 \text { ام. }
$$

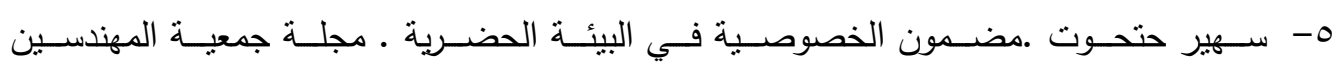

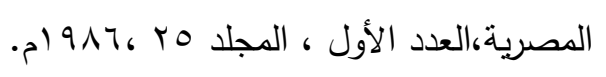

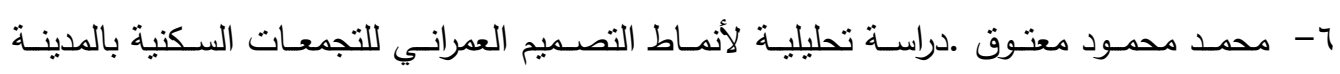

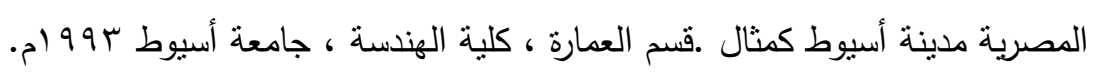


V- محمود عبد الهادي الاكيابي .المضـمون والثـكل في عمـارة المسكن الإسـلامي .ندوة المنهج

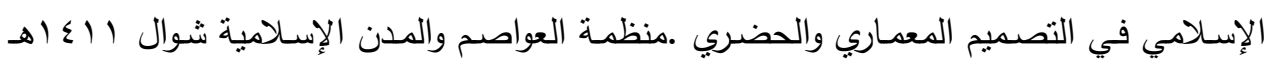

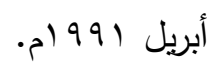

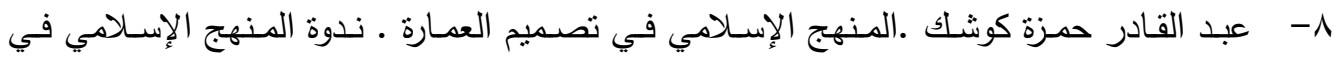

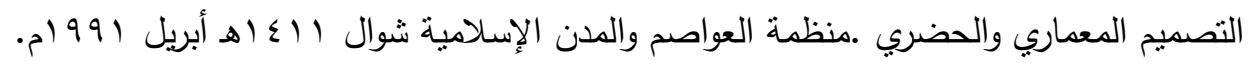

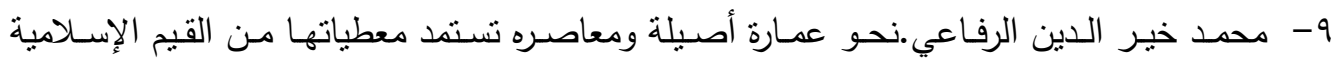

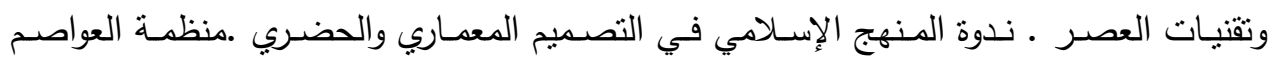

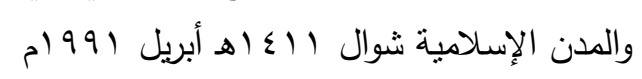

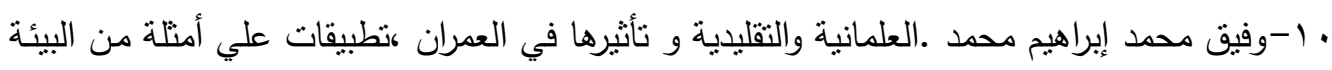
المصرية.قسم العمارة ،كلية الهندسة ، جامعة القاهرة 991 ام. 1ا-هبة عبد الرشيد .دراسة تحليلية لمظاهر وأسباب التلوث البصري في المدينة المصرية المعاصرة .

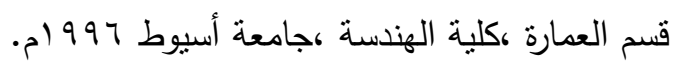

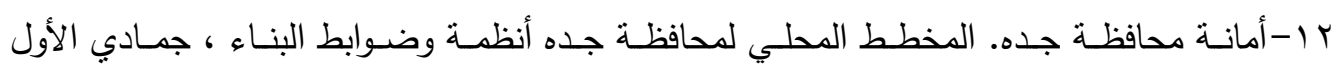
$ه$ ه

rا - احمد هـلال محمد. نمط البنـاء الأفقي الموجهه على الداخل النمـذج الأمثل لعمـارة الصحراء.

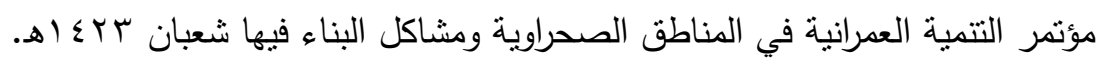

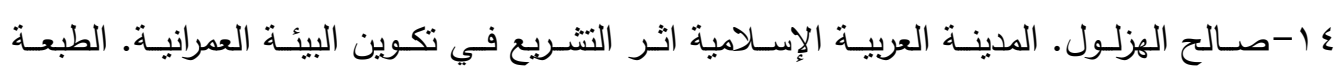

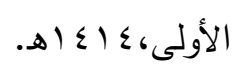

10-احمد هلال محمد ـ تأثثر التغيرات السكانية علي التصميم والتخطبط البيئي في المدينة المصرية.

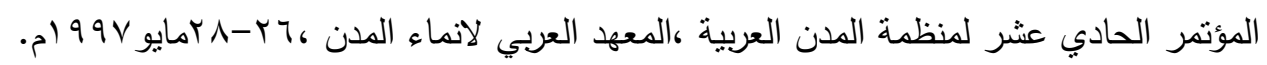

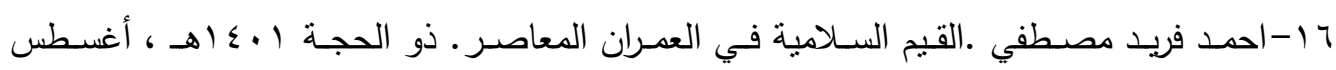
- م) 917

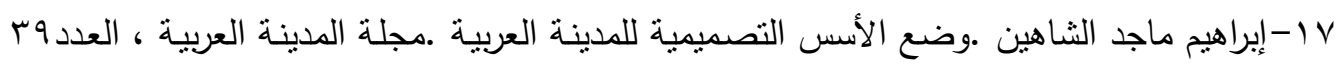

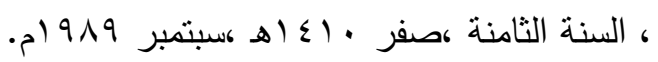

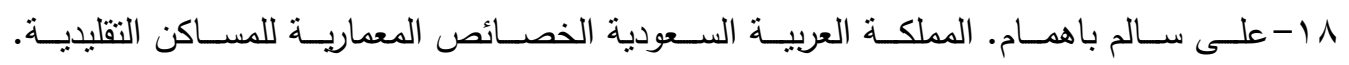
http//www.bab.com.person

19- أثنكال أخذت من أبحاث الطلاب عملت تحت إثراف الباحث عن الخصوصية في أحياء مدينة جده 